Marquette University

e-Publications@Marquette

College of Education Faculty Research and

Publications

Education, College of

$1-2014$

\title{
The Role of Behavioral and Cognitive Cultural Orientation on Mexican American College Students' Life Satisfaction
}

\author{
Lizette Ojeda \\ Texas A \& M University - College Station \\ Lisa M. Edwards \\ Marquette University, lisa.edwards@marquette.edu \\ Erin E. Harding \\ University of Tennessee - Knoxville \\ Brandy Piña-Watson \\ Texas A \& M University - College Station
}

Follow this and additional works at: https://epublications.marquette.edu/edu_fac

Part of the Education Commons

\section{Recommended Citation}

Ojeda, Lizette; Edwards, Lisa M.; Harding, Erin E.; and Piña-Watson, Brandy, "The Role of Behavioral and Cognitive Cultural Orientation on Mexican American College Students' Life Satisfaction" (2014). College of Education Faculty Research and Publications. 361.

https://epublications.marquette.edu/edu_fac/361 
Marquette University

e-Publications@Marquette

\title{
Education Faculty Research and Publications/College of Education
}

This paper is NOT THE PUBLISHED VERSION; but the author's final, peer-reviewed manuscript. The published version may be accessed by following the link in the citation below.

Journal of Hispanic Higher Education, Vol. 13, No. 1 (January 1, 2014): 63-74. DOI. This article is (C SAGE Publications and permission has been granted for this version to appear in e-Publications@Marquette. SAGE Publications does not grant permission for this article to be further copied/distributed or hosted elsewhere without the express permission from SAGE Publications.

\section{The Role of Behavioral and Cognitive Cultural Orientation on Mexican American College Students' Life Satisfaction}

\author{
Lizette Ojeda \\ Texas A\&M University, College Station \\ Lisa M. Edwards \\ Marquette University, Milwaukee, WI \\ Erin E. Hardin \\ University of Tennessee, Knoxville \\ Brandy Piña-Watson \\ Texas A\&M University, College Station
}

\author{
Abstract \\ We examined the role of behavioral (acculturation and enculturation) and cognitive cultural orientation \\ (independent and interdependent self-construal) on Mexican American college students' life satisfaction. \\ Analyses explained $28 \%$ of the variance in life satisfaction, with social class, grade point average, and \\ independent self-construal being unique predictors. Furthermore, enculturation was associated with increasing
}


life satisfaction among those low in interdependent self-construal, whereas acculturation was associated with decreasing life satisfaction among those high in independent self-construal. Implications and directions for future research are discussed.

\section{Keywords}

Mexican Americans, college students, life satisfaction, enculturation, acculturation, self-construal

Latino college students navigate multiple, interwoven life contexts every day, including school, family, work, heritage culture, and mainstream culture. This developmental period of emerging adulthood brings opportunities for growth and well-being, but it can also bring challenges that detract from students' ability to successfully participate in and complete college (Del Pilar, 2009; Ojeda, Navarro, Rosales Meza, \& Arbona, 2012). For Latinos, these challenges include ethnicity-related stressors such as negative social climate, interracial conflict, alienation, intragroup marginalization, and discrimination (Castillo, 2009; Jones, Castellanos, \& Cole, 2002; Lopez, 2005). Researchers have called for a better understanding of the factors that help Latino college students address these challenges and promote college adjustment and well-being, particularly cultural factors (Brown, Wallace, \& Williams, 2001; Yazedjian \& Toews, 2006). Therefore, the purpose of this study was to explore a prominent cultural variable, cultural orientation, and its role on life satisfaction among Mexican American college students. Taking a multidimensional approach to cultural orientation, we investigated how behavioral cultural orientation (i.e., acculturation and enculturation) and cognitive cultural orientation (i.e., independent and interdependent self-construal) contributed to life satisfaction.

Life satisfaction is defined as an individual's subjective appraisal of his or her life (Diener, Emmons, Larsen, \& Griffin, 1985) and has been related to important intra- and interpersonal outcomes (Gilman \& Huebner, 2000), making it a useful indicator of well-being. Research on life satisfaction across many cultures has shown that life satisfaction ratings have been strongly influenced by aspects of culture, including behaviors and cultural beliefs (Suh, Diener, \& Updegraff, 2008). Broadly speaking, how people feel about their culture and what they practice within their cultural context is expected to play a role in their satisfaction with life.

The combination of cultural behaviors and values within a process of adaptation can be understood as acculturation or cultural orientation (Berry, Trimble, \& Olmedo, 1986; Schwartz, Unger, Zamboanga, \& Szapocznik, 2010). This multidimensional process occurs across two axes: adaptation to the host culture (acculturation) and adaptation to the heritage culture (enculturation). Most initial research about acculturation has adopted a unilinear approach, which has situated Latinos, for example, on a continuum between two opposite poles (e.g., European American culture and Latino culture on each end). These models propose that as individuals acculturated to mainstream culture, they move toward the mainstream European American end of the continuum and thus lose their native, Latino culture. Researchers have noted limitations of this framework, as there is no acknowledgment of the possibility that acculturation toward the dominant culture is orthogonal to enculturation in one's culture of origin; in other words, acculturation to dominant culture might not necessarily preclude the simultaneous retention of one's culture of origin (Szapocznik \& Kurtines, 1993). A call for research that separately explores the influence of acculturation toward dominant culture and the maintenance of heritage culture has been issued to better understand the different processes that might emerge (Kim, 2007). For example, Edwards and Lopez (2006) found enculturation predicted life satisfaction among Mexican American adolescents, while acculturation did not.

In addition to moving away from unilinear measures in favor of bilinear measures, multidimensional measures of cultural orientation that assess behaviors and values separately are essential (Miller, 2007). However, some of the most commonly used acculturation scales only assess cultural practices (behavioral cultural orientation), 
rather than cultural values and beliefs (cognitive cultural orientation). Cultural orientation is complex and includes values and identity, and that individuals differ in their cultural practices and adherence to value orientations (Schwartz et al., 2010). For example, a Latino college student may not prefer to speak in Spanish or listen to music in Spanish; however, he or she might still possess a value orientation that emphasizes collectivism and the importance of family (interdependent self-construal). Understanding the complexity of cultural orientation and well-being, therefore, should include behavioral acculturation and enculturation, as well as value orientations (Schwartz et al., 2010; Wang, Schwartz, \& Zamboanga, 2010).

One such value orientation increasingly studied alongside behavioral acculturation (Schwartz, Kim, et al., 2013; Schwartz, Waterman, et al., 2013) is self-construal, which is the way in which individuals perceive themselves in relation to others (Markus \& Kitayama, 1991). Theoretically orthogonal, all individuals possess independent and interdependent self-construals to varying degrees, with cultural context typically strengthening one or the other (Cross, Hardin, \& Gercek-Swing, 2011; Singelis, 1994). An independent selfconstrual, which is usually stronger among individuals from Western cultures such as North America, reflects a belief in the separateness of the self from others and an emphasis on internal abilities, thoughts, and feelings (Markus \& Kitayama, 1991). The independent self-construal reflects ideals of individualism and self-sufficiency and emphasizes socially disengaging behaviors such as asserting or protecting one's own rights (Kitayama, Markus, \& Kurokawa, 2000). Research with Korean and U.S. adults suggested differences in self-construals underlie differences in satisfaction with life, such that those who view themselves in more independent terms evaluated their life satisfaction in a more individualistic manner (Suh et al., 2008). In other words, for individuals who view themselves as independent, life satisfaction is predicted almost exclusively by inner emotional experiences, as opposed to social information.

In contrast to independent self-construal, an interdependent self-construal reflects a view on connectedness, meeting others' expectations, and facilitating interpersonal harmony (Markus \& Kitayama, 1991). Those with an interdependent self-construal value an ability to blend in with the group and may engage in self-criticism more than self-enhancement (Kitayama et al., 2000). An interdependent self-construal has been associated with nonWestern cultures (e.g., Mexican Americans), where socially engaging behavior, such as taking one's proper place in society, is emphasized (Kitayama et al., 2000). For those who view themselves as more interdependent, life satisfaction is predicted not only by inner emotional experiences but also by perceptions of the quality of social relationships (Suh et al., 2008).

Latino culture has been considered a collectivistic culture that emphasizes interdependence and relations among group members and family (Willerton, Dankoski, \& Sevilla Martir, 2008). In contrast, individualist cultures such as U.S. mainstream culture encourage independence, attention to personal opinions and feelings, and autonomy. Many college settings are also shaped around these independent cultural values (Castillo, Conoley, \& Brossart, 2004). Given the heterogeneity within Latino culture, however, assuming individuals will possess certain cultural orientations, because they are from a traditionally collectivist culture is problematic (Willerton et al., 2008). Assessing self-construal as two dimensions, similar to assessing acculturation and enculturation bidimensionally, is therefore important to understand the possibly nuanced relations among these cultural variables. Thus, framed within a multidimensional perspective of cultural orientation (Schwartz et al., 2010), this study examined the role of behavioral cultural orientation through behavioral measures of acculturation and enculturation, as well as the role of cognitive cultural orientation, or value orientations, through independent and interdependent self-construal on the life satisfaction of Mexican American college students. In addition, we examine how the interaction between behavioral and cognitive dimensions of cultural orientation may play a role on life satisfaction. 


\section{Method}

\section{Participants and Procedure}

Participants were recruited from various social and behavioral sciences courses during the beginning of the fall semester. Questionnaires were administered during class and were completed in approximately $35 \mathrm{~min}$. Students were entered into a raffle for a chance to win one of the several gift certificates redeemable at an online store as an incentive for participation. Participants included 349 (62\% females) Mexican American college students attending a Hispanic-Serving Institution (HSI) near the Texas-México border. Ages ranged from 18 to 42 years $(M=20.34, S D=3.45)$. Most were second generation $(43 \%)$, followed by first $(22 \%)$, fourth ( $15 \%)$, third $(10 \%)$, and fifth generation (10\%). Most participants reported their social class as middle class (46\%), followed by working class (33\%), upper-middle class (18\%), and upper class (3\%). Grade point average (GPA) ranged from 1.5 to $4.0(M=3.04, S D=0.51)$ on a 4.0 scale. See Table 1 for sample characteristics.

Table 1. Sample Characteristics.

\begin{tabular}{|l|r|l|}
\hline Demographics & $\%$ & Range \\
\hline Age & & $18-42$ \\
\hline GPA & & $1.5-4.0$ \\
\hline Gender & 38 & \\
\hline Male & 62 & \\
\hline Female & 22 & \\
\hline Generation level & 43 & \\
\hline First & 10 & \\
\hline Second & 15 & \\
\hline Third & 10 & \\
\hline Fourth & & \\
\hline Fifth & 33 & \\
\hline Perceived social class & 46 & \\
\hline Working class & 18 & \\
\hline Middle class & 3 & \\
\hline Upper-middle class & & \\
\hline Upper class &
\end{tabular}

Note. GPA = grade point average.

\section{Instruments}

\section{Behavioral cultural orientation}

The 30-item Acculturation Rating Scale for Mexican Americans-II (ARSMA-II; Cuéllar, Arnold, \& Maldonado, 1995) measures orientation to Mexican (e.g., enculturation) and European American (e.g., acculturation) cultures. The ARSMA-II contains two subscales, the Mexican Orientation Subscale (MOS; 17 items) and the Anglo Orientation Subscale (AOS; 13 items). Sample items for the MOS and AOS include, "I speak Spanish" and "My thinking is done in the English language," respectively, and were measured on a 5-point scale, ranging from 1 (not at all) to 5 (extremely often or almost always). For the present study, the MOS and AOS yielded coefficient alphas of .90 and .65 , respectively.

\section{Cognitive cultural orientation}

The Self-Construal Scale (SCS; Singelis, 1994), the most widely used measure of self-construal (Cross et al., 2011) measures individuals' sense of self in relation to others. This scale consists of two 12-item subscales that measure (a) independent self-construal ("I'd rather say 'no' directly than risk being misunderstood") and (b) 
interdependent self-construal ("I should take into consideration my parents' advice when making education or career plans."). Items are rated on a 7-point scale ranging from 1 (strongly disagree) to 7 (strongly agree). For the present study, $\alpha=.71$ for the Independent and Interdependent subscales.

\section{Life satisfaction}

The five-item Satisfaction With Life Scale (SWLS; Diener et al., 1985) measures individuals' overall life satisfaction. Items (e.g., "If I could live my life over, I would change almost nothing") are measured on a 7-point scale ranging from 1 (strongly disagree) to 7 (strongly agree). For the present study, $\alpha=.75$.

\section{Demographics}

We gathered information about participants' age, gender, grade level, GPA, ethnicity, perceived socioeconomic status, and generation status. Participants' perception of their social class was captured in the single item, "How would you identify your social class?" In the current analyses, GPA and perceived social class were included as control variables.

\section{Results}

The means, standard deviations, reliability coefficients, and correlations for all variables are presented in Table 2. Regression assumptions were tested and no violations were identified. Independent-sample $t$ tests were performed to investigate potential gender differences on all variables. No significant gender differences were found. Acculturation, enculturation, independent self-construal, interdependent self-construal, and life satisfaction were converted into $z$ scores, and interaction terms were created from these standardized scores before conducting further analyses.

Table 2. Descriptive Statistics and Correlations Among Variables.

\begin{tabular}{|l|c|c|c|c|c|c|c|}
\hline Variable & 1 & 2 & 3 & 4 & 5 & 6 & 7 \\
\hline 1. Social class & - & & & & & & \\
\hline 2. GPA & $.15^{*}$ & - & & & & & \\
\hline 3. Acculturation & .03 & .08 & - & & & & \\
\hline 4. Enculturation & -.01 & -.03 & $-.14^{*}$ & - & & & \\
\hline 5. Independent SC & .09 & .05 & $.19^{* *}$ & $.18^{* *}$ & - & & \\
\hline 6. Interdependent SC & -.10 & -.04 & .04 & $.11^{*}$ & $.31^{* *}$ & - & \\
\hline 7. Life Satisfaction & $.31^{* *}$ & $.26^{* *}$ & .05 & $.13^{*}$ & $.29^{* *}$ & $.12^{*}$ & - \\
\hline$M$ & 1.92 & 3.05 & 3.75 & 3.81 & 5.23 & 4.99 & 5.09 \\
\hline$S D$ & .79 & .51 & .45 & .81 & .68 & .69 & 1.13 \\
\hline$\alpha$ & & & .65 & .90 & .71 & .71 & .75 \\
\hline
\end{tabular}

Note. $\mathrm{SC}=$ self-construal; GPA = grade point average.

${ }^{*} p<.05 .{ }^{* *} p<.01$.

We conducted a hierarchical multiple regression analysis (see Table 3 ) to determine the influence of Block 1: Social class and GPA, Block 2: Behavioral cultural orientation (enculturation, acculturation), Block 3: Cognitive cultural orientation (independent self-construal, interdependent self-construal), Block 4: Interaction effects of behavioral and cognitive cultural orientation. Social class and GPA were entered in the first step because the focus of the study was on the effect of cultural orientation on life satisfaction while controlling for these variables. We also wanted to examine how cognitive cultural orientation affected life satisfaction above and beyond behavioral cultural orientation given research on cultural orientation has primarily focused on language use or years in the United States (Schwartz et al., 2010). The final model accounted for $28 \%, F(8,291)=$ $14.20, p<.001$, of the variance in life satisfaction. Unique significant predictors in the overall model included: 
Social class $(\beta=.27, p<.001)$, GPA $(\beta=.23, p<.001)$, and independent self-construal $(\beta=.22, p<.001)$, as well as the interactions between acculturation and independent self-construal $(\beta=-.13, p<.01)$ and between enculturation and interdependent self-construal $(\beta=-.13, p<.05)$. In addition, we used Aiken and West's (1991) simple slopes analysis to determine whether the slopes of the interaction effects were significantly different from zero. Visual representations of the significant interaction effects are presented in Figures 1 and 2.

Table 3. Hierarchical Regression Analysis for Variables Predicting Life Satisfaction.

\begin{tabular}{|l|c|c|c|c|c|}
\hline Variable & $B$ & $S E B$ & 0 & $R^{2}$ & $F$ \\
\hline Block 1 & & & & & \\
\hline Social class & $.37^{* * *}$ & .07 & $.29^{* * *}$ & & \\
\hline GPA & $.47^{* * *}$ & .11 & $.24^{* * *}$ & .16 & $28.56^{* * *}$ \\
\hline Block 2 & & & & & \\
\hline Social class & $.37^{* * *}$ & .07 & $.29^{* * *}$ & & \\
\hline GPA & $.47^{* * *}$ & .10 & $.24^{* * *}$ & & \\
\hline Enculturation & $.17^{* *}$ & .06 & $.16^{* *}$ & & \\
\hline Acculturation & .04 & .06 & .04 & .19 & $16.88^{* * *}$ \\
\hline Block 3 & & & & & \\
\hline Social Class & $.35^{* * *}$ & .07 & $.27^{* * *}$ & & \\
\hline GPA & $.46^{* * *}$ & .10 & $.23^{* * *}$ & & \\
\hline Enculturation & .09 & .06 & .09 & & \\
\hline Acculturation & -.01 & .05 & -.01 & & \\
\hline Interdependent self-construal & .06 & .06 & .06 & & \\
\hline Independent self-construal & $.24^{* * *}$ & .06 & $.24^{* * *}$ & .25 & $16.24^{* * *}$ \\
\hline Block 4 & & & & & \\
\hline Social class & $.34^{* * *}$ & .07 & $.27^{* * *}$ & & \\
\hline GPA & $.45^{* * *}$ & .01 & $.23^{* * *}$ & & \\
\hline Enculturation & .08 & .06 & .08 & & \\
\hline Acculturation & -.04 & .05 & -.04 & & \\
\hline Interdependent self-construal & .06 & .05 & .06 & & \\
\hline Independent self-construal & $.22^{* * *}$ & .05 & $.22^{* * *}$ & & \\
\hline Acculturation $\times$ Independent & $-.11^{* *}$ & .04 & $-.13^{* *}$ & & \\
\hline Enculturation $\times$ Interdependent & $-.12^{*}$ & .05 & $-.13^{*}$ & .28 & $14.20^{* * *}$ \\
\hline
\end{tabular}

Note. GPA = grade point average.

${ }^{*} p<.05 .{ }^{* *} p<.01 . * * * p<.001$.

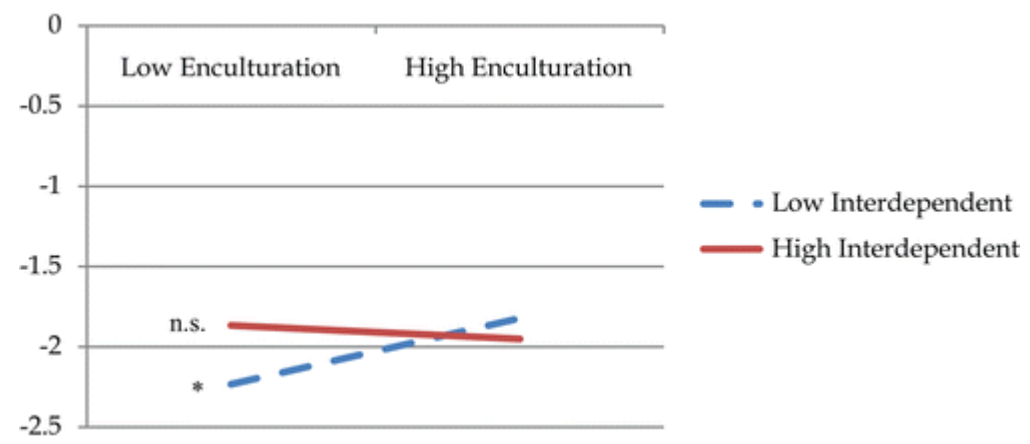

Figure 1. Interaction effect between enculturation and interdependent self-construal on life satisfaction using $z$ scores.

Note. n.s. $=$ nonsignificant. 
$* p<.001$.

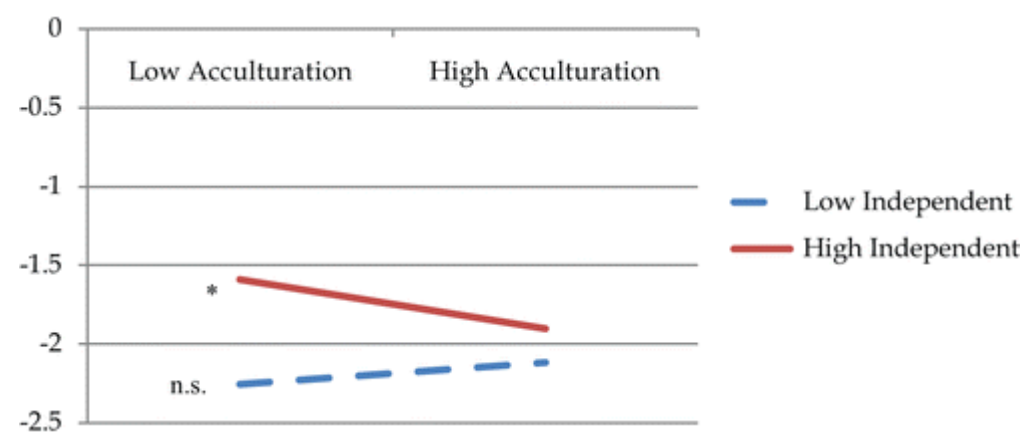

Figure 2. Interaction effect between acculturation and independent self-construal on life satisfaction using $z$ scores.

Note. n.s. $=$ nonsignificant.

${ }^{*} p<.001$.

\section{Discussion}

The current study contributes to our understanding of cultural orientation and life satisfaction in Mexican American college students by exploring the relationship among these variables in a multidimensional manner. Specifically, we moved beyond unilinear and behaviorally focused measures of cultural orientation to include bidimensional measures of behavioral and cognitive dimensions. The relatively small correlations obtained between the behavioral and cognitive measures (e.g., $r=.19$ for acculturation and independent self-construal and $r=.11$ for enculturation and interdependent self-construal) suggest that these are representing related, yet distinct constructs. As such, our findings highlight the importance of investigating these variables separately (Schwartz et al., 2010). College counselors and advisors should inquire about a student's social/leisure activities, as well as how much they value independence or connection to peers and family.

Our regression analyses demonstrated that independent self-construal, but not behavioral acculturation, behavioral enculturation, or interdependent self-construal, was significantly associated with life satisfaction; in other words, Mexican American college students who have a value orientation that focuses on individualism and competition report higher levels of life satisfaction even after controlling for GPA and social class. An independent value orientation may facilitate Mexican American students' ability to meet the demands of the westernized U.S. education system that reflect individualism and autonomy (Castillo et al., 2004) above and beyond other cognitive or behavioral orientations.

Results also revealed interesting moderating relationships between acculturation, enculturation, and independent and interdependent self-construal. Enculturation was related with life satisfaction only among students low in interdependence; higher levels of enculturation (more behaviors characteristic of Mexican culture) was associated with higher life satisfaction, as in past research (e.g., Edwards \& Lopez, 2006). On the other hand, acculturation was associated with life satisfaction among those individuals high in independence; for these Mexican American college students, lower levels of acculturation (fewer behaviors in line with European American culture) was associated with increasing life satisfaction. Taken together, these relations suggest that, for these college students, having less emphasis in one area of cultural orientation benefits from more emphasis in another area. For example, Mexican American college students who highly value independence benefit from engaging in fewer European American, mainstream society behaviors and practices, at least in this predominantly Mexican American context (i.e., HSI near the U.S.-México border). It appears as 
though over-emphasizing behaviors and value orientations in either direction (Mexican American or European American) is associated with lower well-being.

The literature on integration (Berry, 1980) and bicultural competence (LaFromboise, Coleman, \& Gerton, 1993) suggests a similar pattern of increased well-being with a balance of acculturation to mainstream culture and maintenance of heritage culture. Biculturalism is associated with positive outcomes such as lower depression, higher self-esteem, and life satisfaction (Wang et al., 2010), as well as academic outcomes (Ojeda, Flores, \& Navarro, 2011). The Mexican American participants, in our study, although attending an HSI, are still required to operate within an institution that has characteristics reflective of dominant European American society, including access to knowledge and resources that might historically have been reserved for those with privilege (Castillo et al., 2004). The moderation results of our study, therefore, illustrate the importance of emphasizing a cultural orientation to bring balance (and create the condition of "biculturalism") to an individual who may tend to favor one orientation strategy.

As with all studies, limitations exist that should be noted in the interpretation of findings. First, the context of this sample (Mexican American undergraduates, from an HSI) should be acknowledged, as generalizability to other Latino groups is unknown (Umaña-Taylor \& Fine, 2001). Future studies can test similar hypotheses about the role of cultural orientation on life satisfaction with other Latino groups, and within other university contexts. Understanding how Latino students at, predominantly, European American institutions, for example, navigate the demands of interactions with other students and personnel would be informative given Latinos' lowgraduation rates compared with other racial/ethnic groups (Aud et al., 2011).

\section{Implications for Practice}

Despite the limitations of this study and its exploratory nature, our findings suggest several implications for professionals in college settings working with Mexican American students. For example, higher education professionals may serve students well by explicitly incorporating cultural factors into their first-year seminars or other transition activities. Such seminars typically include an introduction to the college campus and important academic skills; however, seminar instructors might also explicitly include discussion of the independent values that characterize institutes of higher education, as well as the importance of maintaining ties to heritage culture and practices. Moreover, in addition to having students conduct a self-assessment of academic strengths and weaknesses, students could be encouraged to conduct a "self-assessment" of cultural behaviors and attitudes to clarify the existing resources they can use to promote their well-being and college success (e.g., resilience, spirituality), as well as deficit areas that could be strengthened by increased attention and/or skill development. Such approach might involve acknowledging that the transition to college requires students to develop a new identity (college student) and to acculturate to a new cultural context (the college community). Beyond the student level, a campus-wide climate that values balance of cultural contexts should be created. Administrators can communicate to faculty, staff, students, and their families that the university values connection to mainstream U.S. culture (e.g., through more individualistic academic endeavors and activities) as well as maintenance of heritage culture (e.g., through initiatives such as programs and events that integrate and celebrate culture), and more importantly, that helping students to be bicultural is likely to improve their wellbeing.

It is clear that additional research is needed to better understand how Mexican American experience well-being within the college context, and how it is affected by their cultural identities and orientations. As future research enhances our understanding of these complex processes, researchers, practitioners, and educators will be better able to meet the needs of the growing Mexican American college student population in the United States. 


\section{Declaration of Conflicting Interests}

The author(s) declared no potential conflicts of interest with respect to the research, authorship, and/or publication of this article.

\section{Funding}

The author(s) received no financial support for the research, authorship, and/or publication of this article.

\section{References}

\begin{tabular}{|c|}
\hline $\begin{array}{l}\text { ken, L. S., West, S. G. (1991). Multiple regression: Testing and interpreting interactions. Newbury Park, } \\
\text { CA: SAGE. }\end{array}$ \\
\hline $\begin{array}{l}\text { Aud, S., Hussar, W., Kena, G., Bianco, K., Frohlich, L., Kemp, J., Tahan, K. (2011). The Condition of Education } \\
2011 \text { (NCES 2011-033). Washington, DC: U.S. Department of Education, National Center for Education } \\
\text { Statistics, U.S. Government Printing Office. }\end{array}$ \\
\hline $\begin{array}{l}\text { Berry, J. W. (1980). Acculturation as varieties of adaptation. In Padilla, A. M. (Ed.), Acculturation: Theory, } \\
\text { models and some new findings (pp. 9-25). Boulder, CO: Westview. }\end{array}$ \\
\hline $\begin{array}{l}\text { Berry, J. W., Trimble, J. E., Olmedo, E. L. (1986). Assessment of acculturation. In Lonner, W. J., Berry, J. W. } \\
\text { (Eds.), Field methods in cross-cultural research (pp. 291-345). Beverly Hills, CA: SAGE. }\end{array}$ \\
\hline $\begin{array}{l}\text { Brown, T. N., Wallace, J. M., Williams, D. R. (2001). Race-related correlates of young adults' subjective well- } \\
\text { being. Social Indicators Research, 53, 97-116. doi:10.1023/A:1007190226538 }\end{array}$ \\
\hline $\begin{array}{l}\text { Castillo, L. G. (2009). The role of intragroup marginalization in Latino college student adjustment. } \\
\text { International Journal for the Advancement of Counselling, 31, 245-254. doi:10.1007/s10447-009- } \\
9081-5\end{array}$ \\
\hline $\begin{array}{l}\text { Castillo, L. G., Conoley, C. W., Brossart, D. F. (2004). Acculturation, white marginalization, and family support } \\
\text { as predictors of perceived distress in Mexican American female college students. Journal of } \\
\text { Counseling Psychology, 51, 151-157. }\end{array}$ \\
\hline $\begin{array}{l}\text { Cross, S. E., Hardin, E. E., Gercek-Swing, B. (2011). The what, how, and why of self-construal. Personality and } \\
\text { Social Psychology Review, 15, 142-179. doi:10.1177/1088868310373752 }\end{array}$ \\
\hline $\begin{array}{l}\text { Cuéllar, I., Arnold, B., Maldonado, R. (1995). Acculturation rating scale for Mexican Americans-II: A revision of } \\
\text { the original ARSMA scale. Hispanic Journal of Behavioral Sciences, 17, 274-304. } \\
\text { doi:10.1177/07399863950173001 }\end{array}$ \\
\hline $\begin{array}{l}\text { Del Pilar, J. A. (2009). Mental health and Latino/a college students: A psychological perspective and new } \\
\text { findings. Journal of Hispanic Higher Education, 8, 163-281. }\end{array}$ \\
\hline $\begin{array}{l}\text { Diener, E., Emmons, R. A., Larsen, R. J., Griffin, S. (1985). The satisfaction with life scale. Journal of Personality } \\
\text { Assessment, 49, 71-75. doi:10.1207/s15327752jpa4901_13 }\end{array}$ \\
\hline $\begin{array}{l}\text { Edwards, L. M., Lopez, S. J. (2006). Perceived family support, acculturation, and life satisfaction in Mexican } \\
\text { American youth: A mixed-methods exploration. Journal of Counseling Psychology, 53, 279-287. } \\
\text { doi:10.1037/0022-0167.53.3.279 }\end{array}$ \\
\hline $\begin{array}{l}\text { Gilman, R., Huebner, E. S. (2000). Review of life satisfaction measures for adolescents. Behaviour Change, } \\
\text { 17, 178-195. doi:10.1375/bech.17.3.178 }\end{array}$ \\
\hline $\begin{array}{l}\text { Jones, L., Castellanos, J., Cole, D. (2002). Examining the ethnic minority student experience at predominantly } \\
\text { White institutions: A case study. Journal of Hispanic Higher Education, 1, 19-39. } \\
\text { doi:10.1177/1538192702001001003 }\end{array}$ \\
\hline $\begin{array}{l}\text { Kim, B. S. K. (2007). Acculturation and enculturation. In Leong, F. T. L., Inman, A. G., Ebreo, A., Yang, L., } \\
\text { Kinoshita, L., Fu, M. (Eds.), Handbook of Asian American psychology (2nd ed., pp. 141-158). Thousand } \\
\text { Oaks, CA: SAGE. }\end{array}$ \\
\hline $\begin{array}{l}\text { Kitayama, S., Markus, H. R., Kurokawa, M. (2000). Culture, emotion, and well-being: Good feelings in Japan } \\
\text { and the United States. Cognition \& Emotion, 14, 93-124. doi:10.1080/026999300379003 }\end{array}$ \\
\hline $\begin{array}{l}\text { LaFromboise, T., Coleman, H. L., Gerton, J. (1993). Psychological impact of biculturalism: Evidence and theory. } \\
\text { Psychological Bulletin, 114, 395-412. doi:10.1037/0033-2909.114.3.395 }\end{array}$ \\
\hline
\end{tabular}


Lopez, J. D. (2005). Race-related stress and sociocultural orientation among Latino students during their transition into a predominantly White, highly selective institution. Journal of Hispanic Higher Education, 4, 354-365. doi:10.1177/1538192705279594

Markus, H. R., Kitayama, S. (1991). Culture and the self: Implications for cognition, emotion, and motivation. Psychological Review, 98, 224-253. doi:10.1037/0033-295X.98.2.224

Miller, M. J. (2007). A bilinear multidimensional measurement model of Asian American acculturation and enculturation: Implications for counseling interventions. Journal of Counseling Psychology, 54, 118131. doi:10.1037/0022-0167.54.2.118

Ojeda, L., Flores, L. Y., Navarro, R. L. (2011). Social cognitive predictors of Mexican American college students' academic and life satisfaction. Journal of Counseling Psychology, 58, 61-71.

Ojeda, L., Navarro, R. L., Rosales Meza, R., Arbona, C. (2012). Too Latino and not Latino enough: The role of ethnicity-related stressors on Latino college students' life satisfaction. Journal of Hispanic Higher Education, 11, 14-28. doi:10.1177/1538192711435553

Schwartz, S. J., Kim, S. Y., Whitbourne, S. K., Zamboanga, B. L., Weisskirch, R. S., Forthun, L. F., Luyckx, K. (2013). Converging identities: Dimensions of acculturation and personal identity status among immigrant college students. Cultural Diversity \& Ethnic Minority Psychology, 19, 155-165. doi:10.1037/a0030753

Schwartz, S. J., Unger, J. B., Zamboanga, B. L., Szapocznik, J. (2010). Rethinking the concept of acculturation: Implications for theory and research. American Psychologist, 65, 237-251. doi:10.1037/a0019330

Schwartz, S. J., Waterman, A. S., Umaña-Taylor, A. J., Lee, R. M., Kim, S. Y., Vazsonyi, A. T., Williams, M. K. (2013). Acculturation and well-being among college students from immigrant families. Journal of Clinical Psychology, 69, 298-318. doi:10.1002/jclp.21847

Singelis, T. M. (1994). The measurement of interdependent self-construals. Personality and Social Psychology Bulletin, 20, 580-591. doi:10.1177/0146167294205014

Suh, E. M., Diener, E., Updegraff, J. A. (2008). From culture to priming conditions: Self-construal influences on life satisfaction judgments. Journal of Cross-Cultural Psychology, 39, 3-15. doi:10.1177/0022022107311769

Szapocznik, J., Kurtines, W. M. (1993). Family psychology and cultural diversity: Opportunities for theory, research and application. American Psychologist, 48, 400-407. doi:10.1037/0003-066X.48.4.400

Umaña-Taylor, A. J., Fine, M. A. (2001). Methodological implications of grouping Latino adolescents into one collective ethnic group. Hispanic Journal of Behavioral Sciences, 23, 347-362. doi:10.1177/0739986301234001

Wang, S., Schwartz, S. J., Zamboanga, B. L. (2010). Acculturative stress among Cuban American college students: Exploring the mediating pathways between acculturation and psychosocial functioning. Journal of Applied Social Psychology, 40, 2862-2887. doi:10.1111/j.1559-1816.2010.00684.x

Willerton, E., Dankoski, M. E., Sevilla Martir, J. F. (2008). Medical family therapy: A model for addressing mental health disparities among Latinos. Families, Systems, \& Health, 26, 196-206. doi:10.1037/10917527.26.2.196

Yazedjian, A., Toews, M. L. (2006). Predictors of college adjustment among Hispanic students. Journal of the First-Year Experience \& Students in Transition, 18, 9-29. 